\title{
Measurements of clothing evaporative resistance using a sweating thermal manikin: an overview
}

\author{
Faming WANG ${ }^{1}$ \\ ${ }^{1}$ Institute of Textiles and Clothing (ITC), The Hong Kong Polytechnic University, Hong Kong \\ Received April 4, 2017 and accepted May 26, 2017 \\ Published online in J-STAGE June 1, 2017
}

\begin{abstract}
Evaporative resistance has been widely used to describe the evaporative heat transfer property of clothing. It is also a critical variable in heat stress models for predicting human physiological responses in various environmental conditions. At present, sweating thermal manikins provide a fast and cost-effective way to determine clothing evaporative resistance. Unfortunately, the measurement repeatability and reproducibility of evaporative resistance are rather low due to the complicated moisture transfer processes through clothing. This review article presents a systematical overview on major influential factors affecting the measurement precision of clothing evaporative resistance measurements. It also illustrates the state-of-the-art knowledge on the development of test protocol to measure clothing evaporative resistance by means of a sweating manikin. Some feasible and robust test procedures for measurement of clothing evaporative resistance using a sweating manikin are described. Recommendations on how to improve the measurement accuracy of clothing evaporative resistance are addressed and expected future trends on development of advanced sweating thermal manikins are finally presented.
\end{abstract}

Key words: Thermal manikin, Apparent evaporative resistance, Sweating, Maximum evaporative capacity, "Heat pipe" effect, Heat stress

\section{Background}

The role of textiles as a prominent heat and moisture barrier has been extensively investigated for many decades ${ }^{1-3)}$. Particularly, many physical parameters have been developed to quantify the heat and moisture transfer properties of textiles ${ }^{4,5)}$. For instance, thermal conductivity, thermal resistance and fabric loft are used to quantify the heat transfer property of textiles. Similarly, water vapor transmission rate, water vapor permeability, absorption rate, wicking time, wetted area/radius, drying time, one-way transfer index, overall moisture management capability (OMMC) index and evaporative resistance are developed to characterize the moisture transfer prop-

To whom correspondence should be addressed.

E-mail: faming.wang@polyu.edu.hk

(C)2017 National Institute of Occupational Safety and Health erty of textiles. Most of the above parameters are used to describe the fabric heat and moisture transfer properties and they provide useful information on selection of materials. Clothing has a three-dimensional configuration, which may trap a great amount of air between clothing layers and the human body. To investigate the effect of clothing on human thermal comfort and thermal stress in different environments, clothing thermal insulation and clothing evaporative resistance should be used ${ }^{6}$.

Clothing thermal insulation (or thermal resistance, $I_{t}$ ) and evaporative resistance (or water vapor resistance, $R_{e t}$ ) can be determined by using a thermal manikin and human subjects $^{7-11)}$. Manikin tests are usually fast, cost-effective and repeatable ${ }^{12)}$. Thermal manikin is a human-shaped heated dummy equipped with heating, sweating systems (if any), measuring temperature sensors and/or heat flux sensors. Since the first thermal manikin developed in 1941, engineers have developed various types of manikins 
including male manikin, female manikin, baby manikin, child manikin, adult manikin and sectional body manikins. Today's modern thermal manikins can mimic human sweating, walking, and/or may also be used for predicting human physiological responses in various thermal conditions ${ }^{12-16)}$. Compared to manikin tests, human tests are more complicated, time-consuming, expensive and ethical issues may be involved ${ }^{12,17,18)}$. For these reasons, only few reported studies have been dedicated to use human subjects to determine clothing insulation and evaporative resistance $^{10,11,47)}$

This review article presents an overview on major influential factors affecting the measurement of clothing evaporative resistance by means of a sweating manikin. Recommendations on how to improve measurement accuracy are proposed and future trends on development of more advanced sweating thermal manikins are discussed. This review article may contribute to enhancing measurement repeatability and reproducibility of clothing evaporative resistance measurements and thereby improving the prediction precision of human thermal comfort and heat stress models.

\section{Evaporative Resistance Measurements by a Sweating Manikin}

Most of today's thermal manikins are designed to be able to measure clothing evaporative resistance ${ }^{12-16,19)}$. Sweating thermal manikins are now available in a variety of sizes (i.e., baby, child, adult and segmental), body shapes (i.e., male or female) and configurations (e.g., copper, plastic, resin shells, epoxy shell, water filled fabric shells). Many sweating manikins have 15-35 body segments (an exception is the ADAM manikin, which has 120 segments) and each body segment can be individually regulated ${ }^{14-18,20)}$. At present, ASTM F2370 (2016) is the only standard with regard to measurements of clothing evaporative resistance using a sweating manikin ${ }^{21}$. Though this standard has been updated for three versions since 2005, almost no big improvement on the test protocol has been made. The 2005 version of the ASTM F2370 standard was developed based on a round-robin sweating manikin study organized by McCullough ${ }^{9}$. Large discrepancies were observed in clothing evaporative resistance values obtained from different participating laboratories. For instance, the evaporative resistance of cold weather clothing reported by NCSU (i.e., the North Carolina State University) is $342 \%$ greater than that reported by DERA (i.e., the Defense Evaluation and Research Agency of UK, which was split into two organizations: QinetiQ Group plc [Hampshire, UK] and Defense Science and Technology Laboratory [RDERA, Salisbury, UK]). The huge discrepancy is probably due to the ambiguous test protocol, i.e., no attempt has been made to control sweating method, test condition as well as test procedure ${ }^{9)}$. In addition to the above factors, the fabric 'skin', sweating rate, the calculation method as well as the sweating body segments can greatly affect test results ${ }^{17,22,23)}$.

\section{Effect of Fabric 'skin'}

For evaporative resistance tests, the simulation of human sweating on manikins is required ${ }^{24-26)}$. The most often used method to achieve this function is to use a piece of stretch and tight fitting knitted fabric 'skin' (see Fig. 1). Presently, there is no standardized fabric 'skin' for sweating thermal manikins and also, no requirement or suggestion on how to select fabric 'skin' has been addressed in ASTM F2370 (2016) ${ }^{23)}$.

The type of fabric 'skin' affects measured clothing evaporative resistance. Both fabric material, structure and fabric thickness greatly affect the moisture contained inside the fabric 'skin' and thereby affect the apparent 'wet' thermal resistance of the fabric 'skin' (i.e., $A I_{\text {wet }}$ ), which is computed by (please refer to Appendix 1$)^{23)}$

$$
A I_{\text {wet }}=\frac{\left(d_{\text {fabric }} \rho_{w}\right)^{2}}{d_{\text {fabric }} \rho^{2}{ }_{w} k_{\text {fiber }}+\left(k_{w}-k_{\text {fiber }}\right) W_{c} m_{\text {fabric }}\left(\rho_{w}+\rho_{\text {fiber }} W_{c}\right)}
$$

where, $d_{\text {fabric }}$ is fabric thickness, $\mathrm{mm} ; k_{\text {fiber }}$, and $k_{w}$ are thermal conductivity of the fiber and water, respectively, $\mathrm{W} /(\mathrm{m} \cdot \mathrm{K}) ; \rho_{\text {fiber }}$ and $\rho_{w}$ are the fiber density and density of water, respectively, $\mathrm{kg} / \mathrm{m}^{3} ; W_{c}$ is moisture content contained in the fabric 'skin', $\%(\mathrm{~g} / \mathrm{g})$.

It can be deduced from Eq. (1) that the apparent 'wet' thermal resistance (or effective thermal resistance) of the fabric 'skin' differs from one another if the fabric material, thickness and moisture contained in the fabric were different. Documented studies have shown that the apparent 'wet' thermal resistance of the existing fabric 'skin' ranges from 0.0051 to $0.0132 \mathrm{~m}^{2} \cdot \mathrm{K} / \mathrm{W}^{22,23,29,31,48)}$. Wang et $a{ }^{23)}$ found that a change in the fabric thickness by $0.50 \mathrm{~mm}$ would result in a change in the apparent 'wet' thermal resistance of $0.0028 \mathrm{~m}^{2} \cdot \mathrm{K} / \mathrm{W}$ (the equation is $A I_{\text {wet }}=0.0055 d_{\text {fabric }}+b$, where $b$ is a constant). Generally, thicker fabric 'skin' tends to have a greater apparent 'wet' thermal resistance, which is similar to the relationship between the fabric thickness and dry thermal resis- 


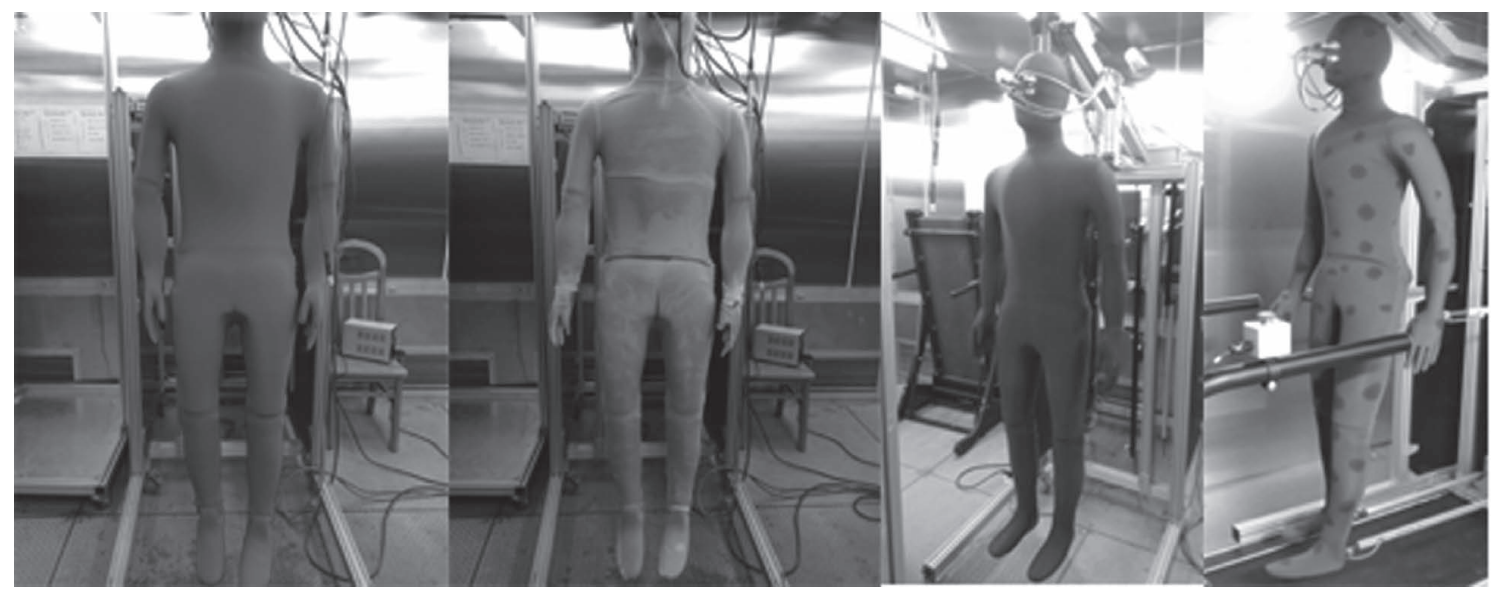

Fig. 1. A 34-segment 'Newton' sweating manikin is wearing different fabric 'skins'

tance $\mathrm{e}^{23,27)}$.

At present, the majority of sweating thermal manikins don't control the fabric 'skin' surface temperature ${ }^{17,28,29)}$. Instead, the manikin surface temperature is controlled. Hence, the temperature on these two surfaces is different due to the presence of fabric 'skin' as well as moisture evaporation taken place on the wet 'skin' surface. The higher the evaporation rate, the larger the temperature difference between the manikin surface and the fabric 'skin' surface. The fabric 'skin' surface temperature is always lower than the controlled manikin surface temperature (i.e., $T_{s k, f}<T_{\text {manikin }}$ ), the reported temperature difference can be up to $5.5^{\circ} \mathrm{C}$ in some test conditions ${ }^{30)}$. If the manikin surface temperature is used for calculating clothing total evaporative resistance, the reported total evaporative resistance will be $>23.7 \%$ greater than its actual value. To enhance test accuracy, the fabric 'skin' temperature should be used for calculating total evaporative resistance. The fabric 'skin' surface temperature can be conveniently determined if the apparent 'wet' thermal resistance of the 'skin' and total heat loss are known, which is normally read as ${ }^{23,29,31)}$

$T_{s k, f}=T_{\text {manikin }}-A I_{\text {wet }} \times H L$

where, $T_{s k, f}$ and $T_{\text {manikin }}$ are the wet fabric 'skin' surface temperature and manikin surface temperature, respectively, ${ }^{\circ} \mathrm{C} ; H L$ is the total heat loss observed from the manikin, i.e., the heating power of the manikin in the isothermal condition, $\mathrm{W} / \mathrm{m}^{2} ; A I_{\text {wet }}$ is the apparent 'wet' thermal resistance (or 'effective' thermal resistance) of the fabric 'skin', $\mathrm{m}^{2} \cdot \mathrm{K} / \mathrm{W}$

Several criteria must be considered in the selection of fabric 'skin'. First, the fabric 'skin' should be specially tai- lored to fit tightly to the manikin body and there is minimal or no air gap(s) between the body and 'skin'. Second, the fabric 'skin' should have good moisture wickability and quick spreading property (i.e., moisture management properties) ${ }^{18)}$. The water released from sweating nozzles can easily be wicked and spread on the outer surface of the 'skin' ${ }^{18)}$. Third, the fabric 'skin' should be good at maintaining a fully saturated surface. Considering the above requirements, a blend of hygroscopic/hydrophilic fibers (e.g., cotton) and spandex is highly recommended to engineer the fabric 'skin'. Besides, the thickness of the fabric 'skin' should be neither too thick nor too thin (i.e., thicker fabric 'skin' will induce a lower fabric 'skin' surface temperature, thin 'skin' contains limited moisture and can easily be dried out during the test) and a medium thickness shall be used (e.g., $0.50 \mathrm{~mm})^{23)}$.

\section{Effects of Sweating Method and Sweating Rate}

Regarding the sweating method, the ASTM F2370 $(2005,2016)$ standard does not stipulate a specific method and also leave the sweating mechanism open for interpretation $^{7}{ }^{21)}$. Basically there are three methods being applied to achieve the simulation of human sweating on thermal manikins ${ }^{17,18,24,32)}$ : pre-wetted tight fabric 'skin' covered on a dry thermal manikin (simply denoted as pre-wetted 'skin' method), manikins equipped with a water supply system to supply water to tight-fitting knitted fabric 'skin' (simply denoted as water supply method) and manikins with a water filled body (or a solid body covered by a saturated fabric 'skin' inner layer and also equipped with a water supply system) covered by a waterproof permeable fabric 'skin' (simply denoted as the permeable 'skin' method). 
The pre-wetted 'skin' method seems to function well but the 'skin' tends to dry out after a certain testing period, which is dependent on the type of clothing tested, the test condition and the initial amount of moisture contained in the 'skin" ${ }^{26,31)}$. The wet test must be concluded when a sharp reduction in the manikin heating power at one or more specific body segments is seen. Clothing total real evaporative resistance (i.e., $R_{e t}$ determined in an isothermal condition) determined by the pre-wetted 'skin' method tends to be lower than that measured using the water supply method because the pre-wetted fabric 'skin' contains a smaller amount of moisture than that in the water supply method $^{32)}$.

The water supply method solved the drying-out issue found in the pre-wetted 'skin' method. Regarding the selection of sweating rate, technicians are advised to strictly follow below steps to carry out the wet test: (1) the fabric 'skin' shall be pre-wetted and saturated before putting it on the manikin; (2) Setting of the sweat rate should be based on the nature of tested clothing and the test condition. The main criterion to choose an appropriate sweating rate should be based on that the assigned sweating rate is able to maintain a fully saturated 'skin' throughout the entire testing period ${ }^{33)}$. Generally, if the tested clothing is impermeable and/or the ambient relative humidity is high (e.g., $\mathrm{RH}>65 \%$ ), a low sweating rate (e.g., $400 \mathrm{~g} \cdot \mathrm{m}^{-2} \cdot \mathrm{h}^{-1}$ ) may already be good enough to keep a fully saturated 'skin' surface. In comparison, if the tested clothing is relatively permeable $\left(i_{m} \geq 0.38\right)$ and/or good at absorbing moisture or the ambient relative humidity is low, a high sweating rate (e.g., $\geq 800 \mathrm{~g} \cdot \mathrm{m}^{-2} \cdot \mathrm{h}^{-1}$ ) should be used. During the wet test, high sweating rates can induce water dripping and may wet tested clothing. In the so-called isothermal condition (i.e., $\left.T_{\text {manikin }}=T_{a}=T_{r}\right)^{34)}$, it is found that wetted clothing doesn't affect clothing total real evaporative resistance. The reason can be explained as follows. Moisture migration from the 'skin' to tested clothing leads to both positive and negative effects on sweat evaporation and evaporative cooling efficiency: 1) the wetting area increases and thereby facilitates sweat evaporation ${ }^{35}$. 2) moisture in tested clothing suppresses evaporation from the 'skin' and/or from inner clothing layer (if any) to the environment because of the increased microclimatic moisture concentration ${ }^{4,24)}$. Besides, if the clothing absorbs the moisture, the moisture takes up air voids within the fabric and between yarns, which blocks moisture evaporation channels. 3) the majority of moisture evaporates from clothing layer(s) and hence the 'skin' cooling efficiency becomes smaller ${ }^{10,50-52)}$. The positive effect may easily be offset by negative effects. Fig-

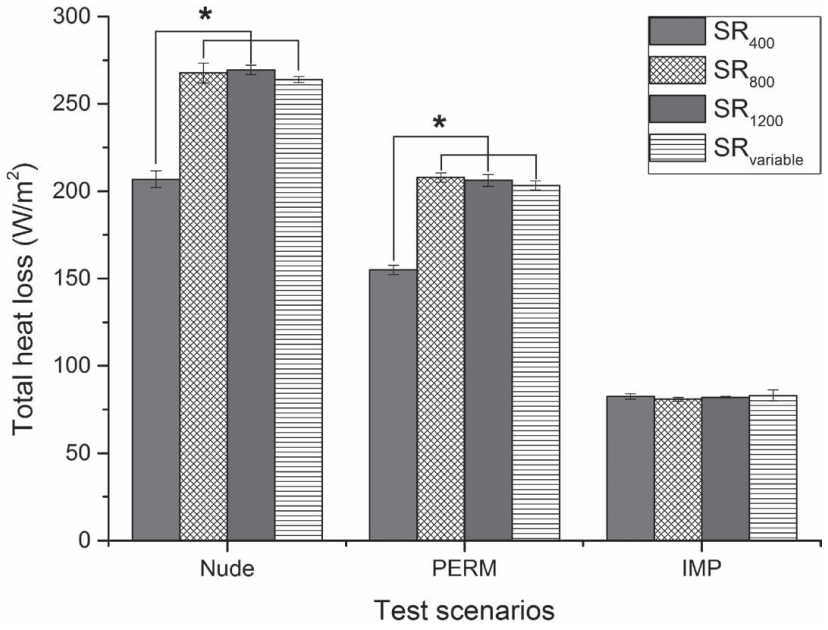

Fig. 2. Effect of sweating set rate on total heat loss of the sweating manikin $^{33)}$ (test condition: $T_{\text {manikin }}=T_{a}=T_{r}=34.0^{\circ} \mathrm{C}, \mathrm{RH}=38-50 \%$, $v_{\text {air }}=0.4 \mathrm{~m} / \mathrm{s}$ ). Nude, the manikin is nude (i.e., wearing only the wet fabric 'skin'); IMP, impermeable clothing, $i_{m}=0.26$; PERM, permeable clothing, $i_{m}=0.50 . \mathrm{SR}_{400}, \mathrm{SR}_{800}, \mathrm{SR}_{1200}$ and $\mathrm{SR}_{\text {variable }}$ denote the segmental sweating rate of the manikin was set to $400,800,1,200 \mathrm{~g} /$ $\left(\mathrm{m}^{2} \cdot \mathrm{h}\right)$ and variable sweating rates, respectively. For $\mathbf{S R}_{\text {variable, }}$ variable segmental sweat rates were used, i.e., head $=1,200 \mathrm{~g} /\left(\mathrm{m}^{2} \cdot \mathrm{h}\right)$ torso $=800 \mathrm{~g} /\left(\mathrm{m}^{2} \cdot \mathrm{h}\right)$, and $\operatorname{limbs}=600 \mathrm{~g} /\left(\mathrm{m}^{2} \cdot \mathrm{h}\right) .{ }^{*}, p<0.05$.

ure 2 shows the effect of four different sweating set rates on total heat loss of the sweating manikin ${ }^{33)}$. No significant effect on the observed total heat loss is found among greater sweating rate scenarios (i.e., $\mathrm{SR}_{800}, \mathrm{SR}_{1200}$ and $\mathrm{SR}_{\text {variable }}$ ) and hence, there is no significant difference in clothing total real evaporative resistances measured under the three sweating rate scenarios. However, significant differences between $\mathrm{SR}_{400}$ and other three sweating scenarios in Nude and PERM are noted because such a small sweating rate fails to maintain a fully saturated 'skin' surface.

In a recent round-robin study ${ }^{36)}$, some participating laboratories are found to try to adjust the sweating rate to ensure the fabric 'skin' is fully saturated and also, no water dripping occurs during the test (e.g., some segments do not sweat or have a low sweating rate [e.g., $<100 \mathrm{ml} /$ $\left.\left.\left(\mathrm{m}^{2} \cdot \mathrm{h}\right)\right]\right)$. This approach can easily lead to a partially driedout 'skin', which will bring significantly errors to the determined clothing total evaporative resistance, i.e., the reported clothing total evaporative resistance will be much greater than its actual value because segmental evaporative heat losses are much smaller in partially or completely dried-out regions than these when they are fully saturated $^{17,22,37)}$. Therefore, it is strongly recommended to set an enough high sweating rate to maintain a fully saturated fabric 'skin' when performing clothing evaporative resistance tests. 
The permeable 'skin' method is adopted by several manikins and those manikins with a permeable 'skin' can keep the tested clothing from getting wet by liquid sweat. A typical example is the 'Walter' fabric sweating mani$\mathrm{kin}^{13)}$. The 'Walter' manikin has a novel design configuration. Unlike many other sweating manikins regulate the manikin surface temperature, the 'Walter' manikin uses RTD (resistance temperature detectors) sensors to measure and control fabric 'skin' surface temperature. This design greatly contributes to enhancing the measurement accuracy of clothing total evaporative resistance. Nevertheless, the 'Walter' manikin has several major design limitations. First, this manikin has only one segment and thus it is unable to measure localized evaporative resistance ${ }^{20)}$. Second, the 'Walter' manikin can only simulate insensible perspiration. It fails to conveniently examine the effect of absorption of liquid sweat by clothing on its heat and mass transfer properties (unless intentionally wetting the tested clothing using liquid water). Besides, the maximum perspiration rate of the waterproof but permeable GoreTex 'skin' is somehow too $\operatorname{low}^{38)}\left(<559 \mathrm{~g} \cdot \mathrm{m}^{-2} \cdot \mathrm{h}^{-1}\right.$, the maximum sweat production rate on the 'Newton' sweating manikin can be up to $\left.2,000 \mathrm{~g} \cdot \mathrm{m}^{-2} \cdot \mathrm{h}^{-1}\right)^{32,33)}$. It is believed that the use of vapor permeable Gore-Tex 'skin' affected water evaporation rate of the manikin, which is mainly determined by the maximum evaporative capacity of the test condition ${ }^{53,54)}$. From a physical viewpoint, the three dominant factors affecting water evaporation rate are the water vapor pressure (temperature and relative humidity), exposed surface area and forced convection ${ }^{33)}$. In such test conditions where the maximum evaporative capacity of the environment (denoted as $E_{\max }$ ) is greater than the maximum allowable perspiration rate of the 'skin' (denoted as $P R_{\max }$, i.e., $E_{\max }>P R_{\max }$ ), clothing evaporative resistances determined using the 'Walter' manikin seem to be incorrect (i.e., the measured evaporative resistances tend to be greater than those determined on the other types of sweating manikin, e.g., the 'Newton' manikin). Figure 3 presents the observed perspiration rate of sweating manikins 'Walter', 'Coppelius' and 'Tore'. 'Tore' uses the pre-wetted 'skin' method while the manikins 'Walter' and 'Coppelius' use the permeable 'skin' method. It can easily be seen that the pre-wetted 'skin' method permits a much greater perspiration rate in both Nude and PERM scenarios than the permeable 'skin' method. In the nude condition for the prewetted 'skin' method, the water vapor pressure gradient between the 'skin' and environment determines the overall perspiration rate $\left(E_{\max }=305.7 \mathrm{~g} \cdot \mathrm{m}^{-2} \cdot \mathrm{h}^{-1}\right.$ in the tested condition). However, for the permeable 'skin' method,

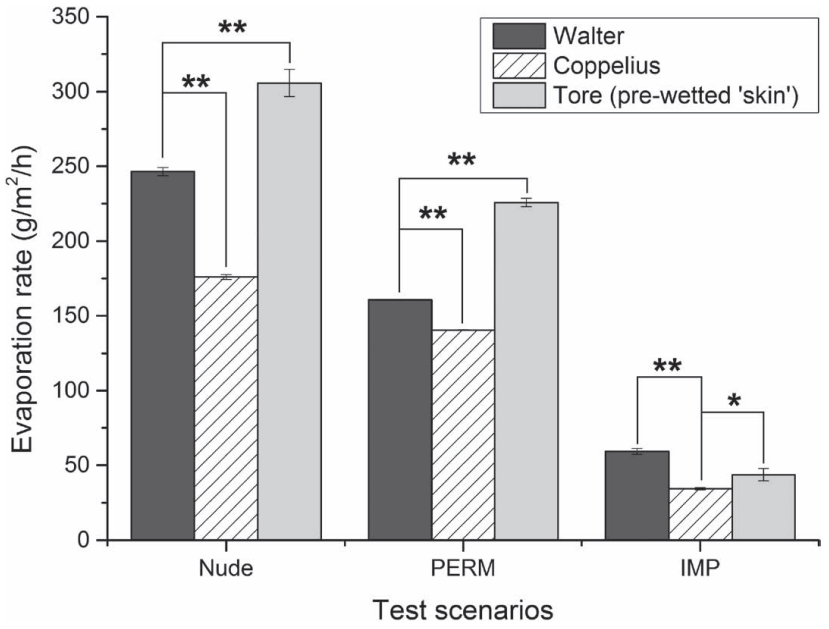

Fig. 3. Comparison of registered perspiration rate on sweating manikins 'Walter', 'Coppelius' and 'Tore' (pre-wetted 'skin') in different clothing scenarios ${ }^{36}$. Nude, the manikin is nude; IMP, impermeable cold weather clothing $\left(i_{m}=0.25\right)$; PERM, permeable clothing (t-shirt and short pants), $i_{m}=0.40$. Test condition: $T_{\text {manikin }}=T_{a i r}=34^{\circ} \mathrm{C}$, $\mathrm{RH}=40 \%, v_{\text {air }}=0.4 \mathrm{~m} / \mathrm{s} .{ }^{* *}, p<0.01 ;{ }^{*}, p<0.05$.

the deciding factor for water evaporation (i.e., how much evaporation is largely decided by the permeable 'skin') is the permeable fabric 'skin' (in the tested condition [i.e., $\left.T_{\text {air }}=34^{\circ} \mathrm{C}, \mathrm{RH}=40 \%, v_{\text {air }}=0.4 \mathrm{~m} / \mathrm{s}\right], P R_{\max }=246.5$ and $176.0 \mathrm{~g} \cdot \mathrm{m}^{-2} \cdot \mathrm{h}^{-1}$ for the 'Walter' and 'Coppelius' manikins, respectively). For impermeable cold weather clothing (i.e., IMP), the observed perspiration rates on these three manikins are relatively close to one another (i.e., below 50 $\mathrm{g} \cdot \mathrm{m}^{-2} \cdot \mathrm{h}^{-1}$ ), which indicate that the water evaporation in impermeable clothing is mainly determined by the tested clothing. Therefore, all the above drawbacks limit the application of the 'Walter' manikin to determine clothing evaporative resistances.

\section{Effect of Test Condition}

The test condition is important to clothing evaporative resistance measurements. The selected test condition should not bring complexity to the measurement. Generally, measurements of clothing evaporative resistance serve for two general purposes: 1) testing purpose, i.e., presenting clothing evaporative resistance in test reports; 2) researching purpose, i.e., investigating the impact of environmental conditions (e.g., actual wear conditions, rain/condensation) on heat and moisture transfer through clothing. Based on the testing purpose, clothing evaporative resistance measurements can be carried out either in isothermal conditions (i.e., $T_{s k, f}=T_{a}=T_{r}$ ) or non-isothermal conditions(i.e., $T_{s k, f} \neq T_{a}$ ). Creating an ideal test condi- 
tion for clothing evaporative resistance tests is important in improving measurement precision. It is highly recommended to perform evaporative resistance measurements in isothermal conditions ${ }^{23,34)}$. Strictly speaking, the conventionally used and accepted condition $T_{\text {manikin }}=T_{a}=T_{r}$ is not an isothermal condition to the fabric 'skin' because there is always a temperature difference between the fabric 'skin' and ambient environment. Perhaps the real isothermal condition (i.e., $T_{s k, f}=T_{a}=T_{r}$ ) can only be achieved on the 'Walter' and 'Coppelius' sweating manikins ${ }^{13-15)}$. The remaining sweating manikins only regulate the manikin surface temperature. Thus, the condition $T_{\text {manikin }}=T_{a}=T_{r}$ may only be referred to as the "so-called" isothermal condition $^{34)}$. Clothing total evaporative resistance determined in either the real isothermal condition or the so-called isothermal condition is called the total real evaporative resistance (i.e., $\left.R_{\text {et, real }}\right)^{7,21,36)}$. Evaporative resistance measured in non-isothermal conditions is always referred to as apparent evaporative resistance (i.e., $\left.A R_{e t}\right)^{7,21}$. Clothing real evaporative resistance and apparent evaporative resistance never exactly equal one another and hence, these two values are not comparable with each other.

In real isothermal conditions, there is no dry heat exchange between the fabric 'skin' and environment so that the observed heating power from the manikin represents the evaporative heat loss. Thus, clothing insulation value is not needed when calculating clothing total real evaporative resistance. In comparison, evaporative resistances measured in non-isothermal conditions may vary greatly from one to another ${ }^{24,26,38,43)}$. The observed non-isothermal total heat loss consists of two components, namely, dry heat loss and evaporative heat loss. The dry heat loss must be known when calculating clothing apparent evaporative resistance. Therefore, clothing thermal insulation tests are needed before performing clothing apparent evaporative resistance tests. Some manikin program requires test operators to enter clothing thermal insulation prior to starting the evaporative resistance test ${ }^{21}$. The evaporative heat loss can be calculated by deducting the dry heat loss from the total heat loss (here it is assumed that condensation and absorption of moisture have a negligible effect on the heat transfer through tested clothing and clothing thermal and evaporative resistances are independent of the air temperature and relative humidity ${ }^{57)}$ ). It is important to note that the dry test and wet test are two different environments and hence, the evaporative heat losses are predicted calculations rather than actual measurements. In fact, the dry heat loss measured in the dry test is never equal to the actual dry heat loss in wetted clothing. The reason is obvious, mois- ture condensation results in an increase in clothing surface temperature due to liberated heat ${ }^{49)}$. Also, the clothing effective thermal conductivity may be increased because of the formation of liquid film on the clothing surface and the absorption of supplied water and condensed water ${ }^{24,39)}$. As a result, the actual dry heat loss should be greater than the measured dry heat loss from dry tests. The reported clothing apparent evaporative resistance is smaller than its actual value accordingly ${ }^{24)}$. Further, it has been reported that condensation-released heat results in increased total heat losses but reduced mass changes (i.e., the heat pipe effect ${ }^{40)}$. Therefore, apparent evaporative resistances calculated by the heat loss and mass loss methods may differ greatly and they are not comparable either. In non-isothermal conditions, the amount of condensation taken place on the surface of tested clothing and/or in clothing layers differs under different testing temperatures. Thus, apparent evaporative resistances may only be compared to those of clothing ensembles tested on the same sweating manikin under the exact same test conditions.

\section{Effect of Calculation Method}

Two calculation methods may be used to calculate clothing total evaporative resistance: the heat loss method and the mass loss method. The calculation equations may be expressed as ${ }^{7)}$

$$
\begin{aligned}
R_{e t} & =\frac{\left(p_{s}-p_{a}\right) \times A}{H_{e}}=\frac{\left(p_{s}-p_{a}\right) \times A}{H_{t}-H_{d}} \\
H_{d} & =\frac{\left(T_{\text {manikin }}-T_{a}\right) \times A}{I_{t}} \\
R_{e t} & =\frac{\left(p_{s}-p_{a}\right) \times A}{\lambda \times \frac{d m}{d t}}
\end{aligned}
$$

where, $R_{e t}$ is the total evaporative resistance of clothing ensemble and surface air layer, $\mathrm{kPa} \cdot \mathrm{m}^{2} / \mathrm{W} ; p_{s}$ is water vapor pressure at the fabric 'skin' surface, $\mathrm{kPa} ; p_{a}$ is water vapor pressure in the ambient air, $\mathrm{kPa} ; A$ is total area of the manikin's sweating surface, $\mathrm{m}^{2} ; H_{t}, H_{d}$ and $H_{e}$ are the total heat loss, dry heat loss and evaporative heat loss observed from the manikin surface, $\mathrm{W}$; In isothermal conditions, $H_{d}=0 ; T_{\text {manikin }}$ and $T_{a}$ are the manikin surface temperature and the ambient temperature, respectively, ${ }^{\circ} \mathrm{C} ; I_{t}$ is the total thermal resistance of the clothing ensemble and boundary air layer, ${ }^{\circ} \mathrm{C} \cdot \mathrm{m}^{2} / \mathrm{W} ; \lambda$ is the heat vaporization of water at the measured surface temperature, $\mathrm{W} \cdot \mathrm{h} / \mathrm{g} ; \lambda=0.6729$ and $0.6735 \mathrm{~W} \cdot \mathrm{h} / \mathrm{g}$ at $T_{s k, f}=35.0^{\circ} \mathrm{C}$ and $34.0^{\circ} \mathrm{C}$, respectively; 
Correction of Clothing Real Evaporative Resistance

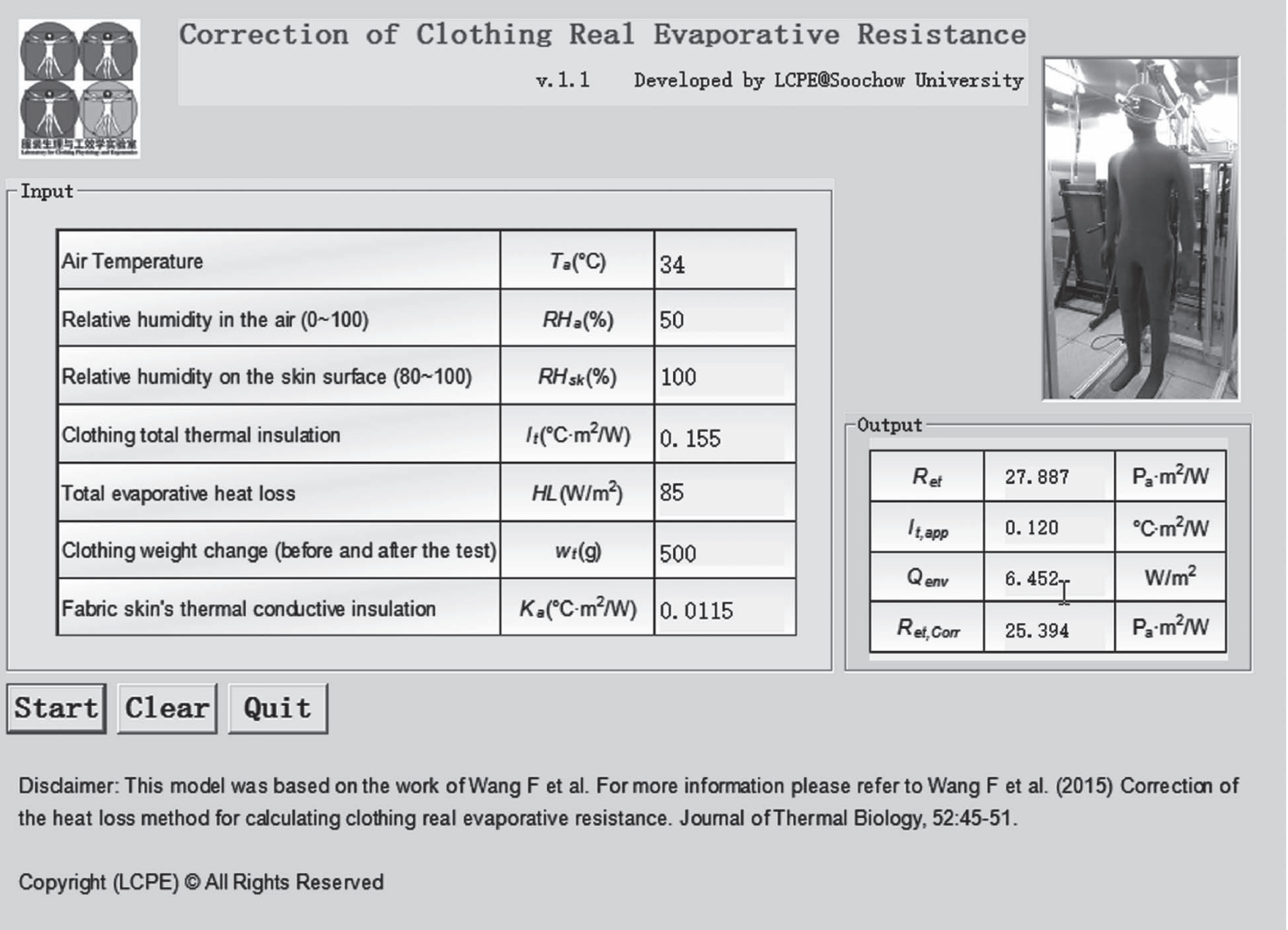

Fig. 4. A schematic diagram of the computer program regarding the correction of clothing total real evaporative resistance determined in the so-called isothermal condition $\left(T_{\text {manikin }}=T_{a i r}=T_{r}\right)$.

$\mathrm{d} m / \mathrm{d} t$ is the evaporation rate of moisture leaving the manikin's sweating surface $(\mathrm{g} / \mathrm{h})$.

Theoretically, both two methods should give the exactly same clothing evaporative resistance in isothermal conditions (i.e., $\left.T_{s k_{f}}=T_{a}=T_{r}\right)^{17,22,41)}$. However, this is not true in the so-called isothermal conditions. In the so-called isothermal condition, the fabric 'skin' temperature is lower than the controlled manikin surface temperature. Hence, the ambient heat will flow into the fabric 'skin' due to the positive temperature difference and this results in greater clothing total real evaporative resistances if the heat loss method is used for calculation. Therefore, the evaporative heat loss measured in the so-called isothermal condition should be corrected before being used to calculate clothing total real evaporative resistance. The correction equation is expressed as $^{22,42)}$

$$
\begin{aligned}
& Q_{\text {evap }} \\
& =Q_{\text {manikin }}^{\prime}+\frac{T_{\text {air }}-T_{\text {sk, }}}{I_{t} \times\left(1-1 \times 10^{-9} \times w_{t}^{3}+1.6 \times 10^{-6} \times w_{t}^{2}-1.004 \times 10^{-3} \times w_{t}\right)}
\end{aligned}
$$

where, $Q_{\text {evap }}$ is the actual total evaporative heat loss, W; $Q_{\text {manikin }}^{\prime}$ is the observed heating power supplied to the manikin during the wet test, $\mathrm{W} ; T_{a i r}$ and $T_{s k, f}$ are the ambient temperature and the fabric 'skin' surface temperature, respectively, ${ }^{\circ} \mathrm{C} ; I_{t}$ is the total static dry thermal insulation of the tested clothing, $\mathrm{m}^{2} \cdot \mathrm{K} / \mathrm{W} ; w_{t}$ is the amount of moisture contained in the tested clothing after the wet test; $0<w_{t}<900 \mathrm{~g}$.

The above correction model is found to be reliable and easy-to-use. A computer program is also developed to correct the clothing total real evaporative resistance calculated by the isothermal heat loss method (see Fig. 4). For wet tests performed in either real or the so-called isothermal conditions, the mass loss method always generates the correct clothing total real evaporative resistance. If the wet tests are performed in non-isothermal conditions, the selection of calculation method should be made with caution. Clothing apparent evaporative resistances calculated by the heat loss and mass loss methods differ in different test conditions and with different types of tested clothing (e.g., permeable, semi-permeable or impermeable cloth- 
ing $)^{43}$. In the non-isothermal condition, the rate of condensation depends on the temperature and moisture distribution within the clothing. Due to the "heat pipe" effect ${ }^{40)}$, the use of apparent evaporative resistance determined by either the heat loss method or the mass loss method may over- or under-estimate the heat stress ${ }^{43-45}$. Therefore, it is suggested to perform the experiments in isothermal conditions and the mass loss method should be used for calculating evaporative resistance. If it is inconvenient to apply the mass loss method for computing clothing total real evaporative resistance, it should be corrected before reporting the values. Recently, the mass loss method has been removed from the ASTM F2370-2016 standard ${ }^{21)}$. The reason why the mass loss method has been deleted is probably because it is challenging to use the mass loss method to calculate localized clothing evaporative resistance (i.e., localized evaporative resistance has been added in ASTM F2370-2016 as Annex A1) ${ }^{21)}$. Nevertheless, it is debatable to exclude the mass loss method from the standard because the method is inherently correct from a physical point of view. The reason why these two methods generated different clothing total real evaporative resistance values is mainly because of a major drawback of manikin design (i.e., the fabric 'skin' temperature is uncontrolled). In addition, all current exiting sweating manikins failed to measure segmental mass loss ${ }^{46}$ and such a design limitation makes it impossible to apply the mass loss method to compute clothing local evaporative resistance.

\section{Effect of Sweating Body Segment}

Most of current existing sweating manikins are segmented (the only exception is the 'Walter' fabric sweating manikin), but some of them do not sweat on the head, hands and feet. Clothing evaporative resistance calculated based on different sweating body segments may differ largely. Similar to the analogy between thermal and electrical resistances, the clothing total evaporative resistance can be written as an analogue of the total equivalent resistance of a set of resistors in a parallel circuit (denoted as $R_{e, \text { total }}$, which is expressed by Eq. (7) ${ }^{55)}$

$$
R_{e, \text { total }}=\frac{1}{\frac{1}{R_{e, 1}}+\frac{1}{R_{e, 2}}+\ldots+\frac{1}{\mathrm{R}_{e, n}}}
$$

where, $R_{e, 1}, R_{e, 2}, \ldots R_{e, n}$ are resistances of resistors $1,2, \ldots$, and $\mathrm{n} ; n$ is the total number of resistors in the parallel circuit.

It can be easily deduced from Eq. (7) that adding/remov-

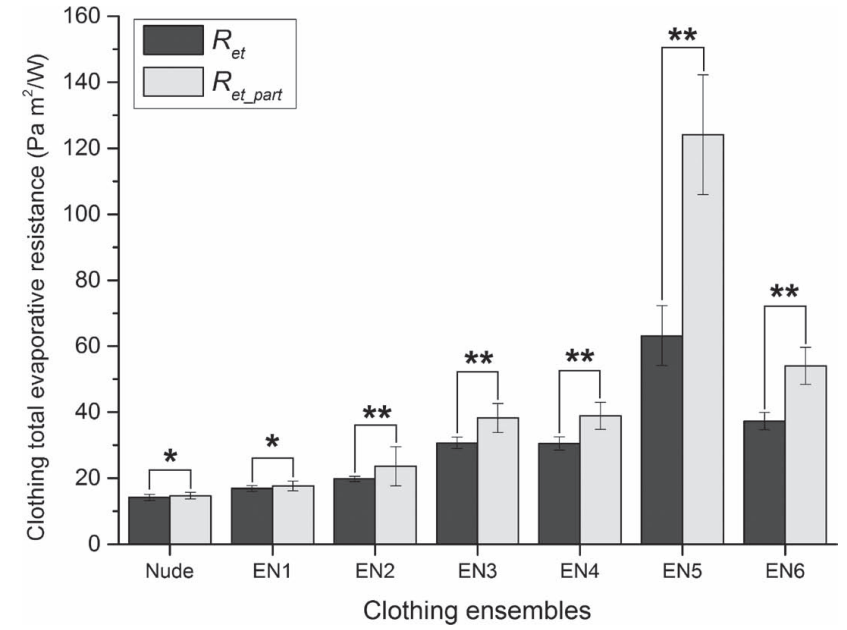

Fig. 5. Effect of sweating body segment on clothing total evaporative resistance ${ }^{36}$. $R_{e t}$, clothing total evaporative resistance calculated based on all sweating body segments; $\boldsymbol{R}_{\text {et,part }}$, clothing total evaporative resistance calculated based on all sweating body segments except the head, hands and feet. Test condition: $\boldsymbol{T}_{\text {manikin }}=\boldsymbol{T}_{a i r}=34.0^{\circ} \mathrm{C}$, $\mathrm{RH}=40 \%, v_{\text {air }}=0.40 \mathrm{~m} / \mathrm{s} .{ }^{*}, p<0.05 ;{ }^{* *}, p<0.01$.

ing a resistor in the parallel circuit ${ }^{56)}$ will decrease/increase the total equivalent resistance. Also, the total resistance should always be smaller than that of the one with the smallest resistance. Any exclusion of sweating body segment(s) from calculation of total evaporative resistance will therefore result in an increment in the clothing total evaporative resistance (see Fig. 5). Theoretically, clothing total evaporative resistance measured using a sweating manikin that does not sweat on head, hands and feet should be greater than that determined using a sweating manikin that does sweat on head, hands and feet $^{36)}$. Particularly, if there is no covering on such segments as the head, hands and feet but with highly insulating clothing layers covering the remaining sweating segments (i.e., inhomogeneous/ uneven distribution of clothing layers over the whole body, e.g., EN5 [see Table 1]), any exclusion of segments with a small localized evaporative resistance will greatly increase the reported total evaporative resistance. In contrast, for homogeneous clothing layer distribution over the sweating body, the exclusion of any sweating segment from calculation of clothing total evaporative resistance seems have a limited impact on the reported total value (e.g., Nude and EN1).

\section{Recommendations and Conclusions}

The repeatability and reproducibility of clothing evaporative resistance measurements can be greatly affected by 
Table 1. Characteristics of clothing ensembles

\begin{tabular}{clcc}
\hline Ensemble & \multicolumn{1}{c}{ Clothing components } & No. of layer & $I_{t}^{*}$ (clo) \\
\hline EN 1 & $\begin{array}{l}\text { Briefs (65\% polyamide, 27\% polyester, 8\% elastane), Body mapping cycling wear, socks (76\% wool, 23\% } \\
\text { polyamide, 1\% Lycra) }\end{array}$ & 1 \\
EN 2 & $\begin{array}{l}\text { Briefs (65\% polyamide, 27\% polyester, 8\% elastane), summer work wear: short sleeve t-shirt, short pants, socks } \\
\text { (76\% wool, 23\% polyamide, 1\% Lycra) }\end{array}$ & 1 \\
EN 3 & $\begin{array}{l}\text { Briefs (65\% polyamide, 27\% polyester, 8\% elastane), short sleeve t-shirt, one-layer jacket (100\% polyester), } \\
\text { trousers (96\% polyamide, 4\% Lycra), socks (76\% wool, 23\% polyamide, 1\% Lycra) }\end{array}$ & 2 \\
EN 4 & $\begin{array}{l}\text { Briefs (91\% polyamide, 9\% elastane), underwear (97\% Outlast, 3\% Spandex), Polartec fleece jacket, fleece } \\
\text { trousers (100\% polyester), sports socks (72\% cotton, 26\% polyamide, 2\% Lycra) }\end{array}$ & 2 \\
EN 5 & $\begin{array}{l}\text { Briefs (91\% polyamide, 9\% elastane), jacket (combined with Dever foder), Barton trousers, Polartec power } \\
\text { trousers, Polartec sweater, sports socks (72\% cotton, 26\% polyamide, 2\% Lycra }{ }^{\mathbb{B}} \text { ) }\end{array}$ & 3 \\
EN 6 & $\begin{array}{l}\text { Briefs (91\% polyamide, 9\% elastane), underwear (100\% polyester), Gore-Tex coverall, sports socks (72\% } \\
\text { cotton, 26\% polyamide, 2\% Lycra) }\end{array}$ & 2 \\
\hline
\end{tabular}

* $I_{t}$, the total clothing thermal insulation was measured using a 'Newton' thermal manikin. It was calculated based on all manikin's segments excluding the head (face), hands and feet.

manikin configuration (e.g., sweating method, temperature control), the fabric 'skin', sweating rate, test condition, and calculation method (including calculation options and sweating body segments). It is highly recommended to carry out clothing evaporative resistance tests in an isothermal condition. At present, the real isothermal condition (i.e., $T_{s k, f}=T_{a}=T_{r}$ ) may only be achieved on 'Walter' and 'Coppelius' type sweating manikins. Due to major drawbacks in manikin configuration design (e.g., the fabric 'skin' temperature is left uncontrolled, segmental mass losses are left undetermined), most current existing sweating manikins reported greater clothing total real evaporative resistance and hence, the evaporative heat loss observed in the so-called isothermal condition (i.e., $T_{\text {manikin }}=T_{a}=T_{r}$ ) should be corrected. The mass loss method is suggested to calculate clothing total real evaporative resistance if the sweating manikin is able to measure the total mass loss in the real or so-called isothermal conditions. Apparent evaporative resistance of ensembles can only be compared to those of other ensembles measured using the same sweating manikin under the same ambient conditions and also calculated by the same method. On the other hand, human subject data provide valuable information about the dynamic character and individual variability of clothing apparent evaporative resistance under actual field conditions. Therefore, comparisons of apparent evaporative resistance data measured on sweating manikins and human subjects are encouraged to further validate manikin data and to explore the manikin-human correlation.

Further, the ASTM F2370-2016 standard should be improved by clearly specifying the requirements on knitted fabric 'skin', test condition and such manikin design configurations as sweating method and temperature control. It is recommended to perform clothing evaporative resistance in isothermal conditions only. Also, the mass loss method should be included in the standard because the mass loss method is inherently correct and reliable. More advanced sweating manikins should be developed in the future. Advanced sweating manikins are expected to be able to control the surface temperature and relative humidity of the fabric 'skin'. They should be designed to mimic human sweating more realistically. Additionally, future advanced sweating manikins will be able to measure segmental mass loss.

\section{References}

1) Woodcock AH (1962) Moisture transfer in textile systems, Part I. Text Res J 32, 628-33. [CrossRef]

2) Gagge AP, Burton AC, Bazett HC (1941) A practical system of units for the description of the heat exchange of man with his environment. Science 94, 428-30. [Medline] [CrossRef]

3) Niven CD (1959) The heat transmission of fabric in wind. Text Res J 29, 826-33. [CrossRef]

4) Das B, Das A, Kothari VK, Fanguiero R, de Araujo M (2007) Moisture transmission through textiles. Part I: Processes involved in moisture transmission and the factors at play. AUTEX Res J 7, 100-10.

5) Luikov AV, Shashkov AG, Vasiliev LL, Fraiman YE (1968) Thermal conductivity of porous systems. Int J Heat Mass Transfer 11, 117-40. [CrossRef]

6) Xu X, Rioux TP, Potter AW (2014) Fabric thermal resistance and ensemble thermal resistances are two different concepts. J Occup Environ Hyg 11, D187-8. [Medline] [CrossRef]

7) ASTM F2370 (2005) Standard test method for measuring the evaporative resistance of clothing using a sweating manikin. American Society for Testing and Materials, West Conshohocken, PA.

8) Richards MGM, McCullough EA (2005) Revised interlabo- 
ratory study of sweating thermal manikins including results from the sweating agile thermal manikin. J ASTM Int 2, $1-13$. [CrossRef]

9) McCullough EA (2001) Interlaboratory study of sweating manikins. In: Proceedings of the 4th International Meeting on Thermal Manikins (4IMM), Richards MGM (Ed.), 1-4, St. Gallen, Switzerland.

10) Holmér I, Elnäs S (1981) Physiological evaluation of the resistance to evaporative heat transfer by clothing. Ergonomics 24, 63-74. [Medline] [CrossRef]

11) Caravello V, McCullough EA, Ashley CD, Bernard TE (2008) Apparent evaporative resistance at critical conditions for five clothing ensembles. Eur J Appl Physiol 104, 361-7. [Medline] [CrossRef]

12) Holmér I (2004) Thermal manikin history and applications. Eur J Appl Physiol 92, 614-8. [Medline] [CrossRef]

13) Fan J, Chen YS (2002) Measurement of clothing thermal insulation and moisture vapour resistance using a novel perspiring fabric thermal manikin. Meas Sci Technol 13, 1115-23. [CrossRef]

14) Varheenmaa $M$ (2014) A new generation sweating thermal manikin for the evaluation of the thermoregulation properties of protective clothing. In: Proceedings of the 10th International Meeting on Thermal Manikin and Modeling (10i3m), Varheenmaa M (Ed.), 1-5, Tampere, Finland.

15) Meinander H (1992) Coppelius-a sweating thermal manikin for the assessment of functional clothing. In: Proceedings of Nokobetef IV: Quality and Usage of Protective Clothing, Meinander H (Ed.), 157-61, Kittilä, Finland.

16) Richards MGM, Mattle N (2001) A sweating thermal manikin (SAM) developed to test complete clothing systems under normal and extreme conditions. In: RTO HFM Symposium, Blowing Hot and Cold: Protecting against climatic extremes. Vol. 4, 1-7.

17) Wang F (2011) Clothing evaporative resistance: its measurements and application in prediction of heat strain $(\mathrm{PhD}$ dissertation). Lund University, Lund, Sweden.

18) Koelblen B, Psikuta A, Bogdan A, Annaheim S, Rossi RM (2017) Comparison of fabric skins for the simulation of sweating on thermal manikins. Int J Biometeorol 61, 151929 (doi:10.1007/s00484-017-1331-3). [Medline] [CrossRef]

19) McCullough EA (2009) Evaluation of cold weather clothing using manikins. In: Textiles for Cold Weather Apparel, Williams JT (Ed.), 244-55. [CrossRef]

20) Wang F, del Ferraro S, Lin LY, Sotto Mayor T, Molinaro V, Ribeiro M, Gao C, Kuklane K, Holmér I (2012) Localised boundary air layer and clothing evaporative resistances for individual body segments. Ergonomics 55, 799-812. [Medline] [CrossRef]

21) ASTM F2370 (2016) Standard test method for measuring the evaporative resistance of clothing using a sweating manikin. American Society of Testing and Materials, West Conshohocken, PA.

22) Wang F, Zhang C, Lu Y (2015) Correction of the heat loss method for calculating clothing real evaporative resistance.
J Therm Biol 52, 45-51. [Medline] [CrossRef]

23) Wang F, Lai D, Shi W, Fu M (2017) Effects of fabric thickness and material on apparent 'wet' conductive thermal resistance of knitted fabric 'skin' on sweating manikins. J Therm Biol (doi:10.1016/j.jtherbio.2017.03.004). [CrossRef]

24) Gao C, Holmér I (2006) Initial, transient and steady state evaporative resistance of impermeable protective clothing. In: Proceedings of the 6th International Meeting on Thermal Manikin and Modeling (6I3M), Fan J (Ed.), 253-61, Hong Kong.

25) Holmér I (2006) Protective clothing in hot environments. Ind Health 44, 404-13. [Medline] [CrossRef]

26) Wang F, Gao C, Kuklane K, Holmér I (2009) A study on evaporative resistances of two skins designed for thermal manikin Tore under different environmental conditions. J Fiber Bioeng Inform 1, 301-5.

27) Slater FP, Rees WH (1946) The protective value of clothing. J Textil Inst Proc 37, 132-53. [CrossRef]

28) Wang F (2009) A preliminary study on the wet cotton fabric 'skin' for the 'Tore' thermal manikin. Technical Report, Lund University. Unpublished work.

29) Wang F, Kuklane K, Gao C, Holmér I (2010) Development and validity of a universal empirical equation to predict skin surface temperature on thermal manikins. J Therm Biol 35, 197-203. [CrossRef]

30) Wang F, Kuklane K, Gao C, Holmér I (2012) Effect of temperature difference between manikin and wet fabric skin surfaces on clothing evaporative resistance: how much error is there? Int J Biometeorol 56, 177-82. [Medline] [CrossRef]

31) Wang F, Kuklane K, Gao C, Holmér I, Havenith G (2011) Development and validity of an empirical equation to predict wet fabric skin surface temperature of thermal manikins. J Fiber Bioeng Inform 3, 9-15.

32) Lu Y, Wang F, Peng H (2016) Effect of two sweating simulation methods on clothing evaporative resistance in a socalled isothermal condition. Int J Biometeorol 60, 1041-9. [Medline] [CrossRef]

33) Lu Y, Wang F, Peng H, Shi W, Song G (2016) Effect of sweating set rate on clothing real evaporative resistance determined on a sweating thermal manikin in a so-called isothermal condition $($ Tmanikin $=\mathrm{Ta}=\mathrm{Tr})$. Int J Biometeorol 60, 481-8. [Medline] [CrossRef]

34) Wang F, Gao C, Kuklane K, Holmér I (2011) Determination of clothing evaporative resistance on a sweating thermal manikin in an isothermal condition: heat loss method or mass loss method? Ann Occup Hyg 55, 775-83. [Medline]

35) Gao C, Holmér I, Fan J, Wan X, Wu JYS, Havenith G (2006) The comparison of thermal properties of protective clothing using dry and sweating manikins. The 3rd European Conference on Protective Clothing (ECPC) and NOKOBETEF 8, 1-6, Gdynia, Poland.

36) Wang F, Havenith G, Mayor TS, Kuklane K, Léonard J, Zwolinska M, Hodder S, Wong C, Kishino J, Dai X (2014) 
Clothing real evaporative resistance determined by means of a sweating thermal manikin: a new round-study study. In: Proceedings of the 10th International Meeting on Thermal Manikin and Modeling (10i3m), Varheenmaa M (Ed.), 1-7, Tampere, Finland.

37) Wang F, Gao C, Kuklane K, Holmér I (2012) A comparison of three different calculation methods for clothing evaporative resistance. In Proceedings of The 5th European Conference on Protective Clothing (ECPC) and NOKOBETEF 10, 1-3, Valencia, Spain.

38) Qian X, Fan J (2006) A comparative investigation of clothing moisture vapour resistance measured under isothermal and non-isothermal conditions. In: Proceedings of the 6th International Meeting on Thermal Manikin and Modeling (6i3m), Fan J (Ed.), 278-84, Hong Kong.

39) Richards MG, Rossi R, Meinander H, Broede P, Candas V, den Hartog E, Holmér I, Nocker W, Havenith G (2008) Dry and wet heat transfer through clothing dependent on the clothing properties under cold conditions. Int J Occup Saf Ergon 14, 69-76. [Medline] [CrossRef]

40) Havenith G, Richards MG, Wang X, Bröde P, Candas V, den Hartog E, Holmér I, Kuklane K, Meinander H, Nocker W (2008) Apparent latent heat of evaporation from clothing: attenuation and "heat pipe" effects. J Appl Physiol (1985) 104, 142-9. [Medline] [CrossRef]

41) Yu W, Wu YS, Fan JT (2011) Effect of posture positions on the evaporative resistance and thermal insulation of clothing. Ergonomics 54, 301-13. [Medline] [CrossRef]

42) Wang F, Shi W, Lu Y, Song G, Rossi RM, Annaheim S (2016) Effects of moisture content and clothing fit on clothing apparent 'wet' thermal insulation: a thermal manikin study. Text Res J 86, 57-63. [CrossRef]

43) Havenith G, Richards M, Wang X, Bröde P, Candas V, den Hartog E, Holmér I, Kuklane K, Meinander H, Nocker W (2008) Use of clothing vapour resistance values derived from manikin mass losses or isothermal heat losses may cause severe under and over estimation of heat stress. In: Proceedings of the 7th International Meeting on Thermal Manikin and Modeling (7i3m), Silva MCG (Ed.), 1-2, Coimbra, Portugal.

44) Wang F, Kuklane K, Gao C, Holmér I (2011b) Can the PHS model (ISO7933) predict reasonable thermophysiological responses while wearing protective clothing in hot environments? Physiol Meas 32, 239-49. [Medline] [CrossRef]

45) Malchaire JBM (2006) Occupational heat stress assessment by the Predicted Heat Strain model. Ind Health 44, 380-7. [Medline] [CrossRef]
46) Wang F, Kuklane K (2012) Comments on "Correction of the evaporative resistance of clothing by the temperature of skin fabric on a sweating and walking thermal manikin". Text Res J 82, 1827-9. [CrossRef]

47) Bernard TE, Ashley CD (2016) Comparison of static total evaporative resistance to apparent total evaporative resistance and WBGT-based clothing adjustment values. In: Proceedings of the 11th International Meeting on Thermal Manikin and Modeling (11i3m), Wang F (Ed.), 26, Suzhou, China.

48) Ueno S, Sawada SI (2012) Correction of the evaporative resistance of clothing by the temperature of skin fabric on a sweating and walking thermal manikin. Text Res J 82, 1143-56. [CrossRef]

49) Lotens WA, van de Linde FJG, Havenith G (1995) Effects of condensation in clothing on heat transfer. Ergonomics 38, 1114-31. [Medline] [CrossRef]

50) Wang F, Annaheim S, Morrissey M, Rossi RM (2014) Real evaporative cooling efficiency of one-layer tight-fitting sportswear in a hot environment. Scand J Med Sci Sports 24, e129-39. [Medline] [CrossRef]

51) Havenith G, Bröde P, den Hartog E, Kuklane K, Holmér I, Rossi RM, Richards M, Farnworth B, Wang X (2013) Evaporative cooling: effective latent heat of evaporation in relation to evaporation distance from the skin. J Appl Physiol (1985) 114, 778-85. [Medline] [CrossRef]

52) Kerslake DMcK (1972) The stress of hot environments. Cambridge University Press, Cambridge.

53) Clifford J, Kerslake DMK, Waddell JL (1959) The effect of wind speed on maximum evaporative capacity in man. $\mathrm{J}$ Physiol 147, 253-9. [Medline] [CrossRef]

54) Givoni B, Goldman RF (1972) Predicting rectal temperature response to work, environment, and clothing. J Appl Physiol 32, 812-22. [Medline]

55) Baehr HD, Stephan K (2006) Heat and Mass Transfer. Second Edition. Springer, Berlin. [CrossRef]

56) Kuklane K, Gao C, Wang F, Holmér I (2012) Parallel and serial methods of calculating thermal insulation in European manikin standards. Int J Occup Saf Ergon 18, 171 -9. [Medline] [CrossRef]

57) Ross K, Barker R, Deaton AS (2012) Translation between heat loss measured using guarded sweating hot plate, sweating thermal manikin, and physiological assessed heat stress of firefighter turnout ensembles. In: Shepherd AM (Ed.), Performance of Protective Clothing and Equipment: Emerging Issues and Technologies, STP1544, 27-47. 


\section{Appendix 1: Influential factors affecting the apparent 'wet' thermal resistance of knitted fabric 'skin' of sweating manikins}

The fabric 'skin' is considered as a porous textile containing a very large quantity of yarns knitted out of fibers. Pores are evenly distributed in the fabric system. The thermal conductivity of porous fabric 'skin' and moisture content contained in the 'skin' are assumed to be constant. Both dry and wet fabric 'skin's are in thermal equilibrium among all phases due to low air velocities applied and the small dimension of fibers. The temperature and moisture content are uniform throughout the fabric material at known values. In addition, volume changes of the fibers due to moisture content (i.e., fiber swelling) are neglected. The thermal conductivity of the water is approximately 25 times that of air, and hence, the contribution to thermal conductivity of fully saturated fabric 'skin' from air and water vapour can be neglected.

For a porous fabric 'skin', $\varepsilon_{0}$ and $\varepsilon$ are porosities without and with water on the surface of the fabric 'skin', respectively, which are related by

$\varepsilon=\varepsilon_{0}-\frac{\rho_{\text {fiber }}}{\rho_{w}}\left(1-\varepsilon_{0}\right) W_{c}$

where, $\rho_{f i b e r}$ and $\rho_{w}$ are densities of the fiber and the liquid water, respectively, $\mathrm{kg} / \mathrm{m}^{3} ; W_{c}$ is the water content contained in fabric, $\%(\mathrm{~g} / \mathrm{g})$.

For a fully saturated porous fabric 'skin', the total effective thermal conductivity (i.e., $k_{\text {wet.fabric }}$ ) of volumetric weighted averages of the fiber and liquid water is calculated by

$k_{\text {wet, fabric }}=k_{\text {fiber }}+\left(k_{w}-k_{f i b e r}\right)\left[\frac{\rho_{\text {fiber }}(1-\varepsilon)}{\rho_{w}} W_{c}\right]$

where, $k_{f i b e r}$ and $k_{w}$ are thermal conductivity of the fiber and water respectively, $\mathrm{W} /(\mathrm{m} \cdot \mathrm{K})$.

Substituting Eq. (A-1) to Eq. (A-2), the total thermal conductivity of the mixed water and fiber (i.e., the wet fabric) is written as

$k_{\text {wet, fabric }}=k_{\text {fiber }}+\left(k_{w}-k_{\text {fiber }}\right)\left[\left(1-\varepsilon_{0}\right) \frac{\rho_{\text {fiber }}}{\rho_{w}} W_{c}\left(1+\frac{\rho_{\text {fiber }}}{\rho_{w}} W_{c}\right)\right]$

The apparent 'wet' thermal resistance of the wet fabric 'skin' (i.e., $\left.A I_{\text {wet }}, \mathrm{m}^{2} \cdot \mathrm{K} / \mathrm{W}\right)$ is computed by

$A I_{\text {wet }}=\frac{d_{\text {fabric }}}{k_{\text {wet } \text { fabric }}}=\frac{d_{\text {fabric }}}{k_{\text {fiber }}+\left(k_{w}-k_{\text {fiber }}\right)\left[\left(1-\varepsilon_{0}\right) \frac{\rho_{\text {fiber }}}{\rho_{w}} W_{c}\left(1+\frac{\rho_{\text {fiber }}}{\rho_{w}} W_{c}\right)\right]}$

where, $d_{\text {fabric }}$ is the fabric thickness, $\mathrm{mm}$.

The porosity on the surface of the dry fabric conditioned at the standard ambient environment may be expressed as

$\varepsilon_{0}=1-\frac{m_{\text {fabric }}}{d_{\text {fabric }} \rho_{\text {fiber }}}$

where, $m_{\text {fabric }}$ is the mass per unit area of the porous textile fabric 'skin', $\mathrm{g} / \mathrm{m}^{2}$;

By combing Eq. (A-5) with Eq. (A-4), we finally have

$A I_{\text {wet }}=\frac{\left(d_{\text {fabric }} \rho_{w}\right)^{2}}{d_{\text {fabric }} \rho^{2}{ }_{w} k_{\text {fiber }}+\left(k_{w}-k_{\text {fiber }}\right) W_{c} m_{\text {fabric }}\left(\rho_{w}+\rho_{\text {fiber }} W_{c}\right)}$

Eq. (A-6) 